\title{
Changes in the Hematopoietic System and Blood Under the Influence of Heavy Metal Salts Can Be Reduced with Vitamin E
}

\author{
Anatolii ROMANIUK, Mykola LYNDIN, Yulia LYNDINA, Vladyslav SIKORA, Natalia HRINTSOVA, \\ Olena TIMAKOVA, Olena GUDYMENKO, Oksana GLADCHENKO
}

Department of Pathology, Sumy State University, SUMY, UKRAINE

\begin{abstract}
Objective: The aim of our work was to study the blood parameters and bone marrow morphological changes in rats exposed to increased amounts of heavy metal salts and the effect of vitamin E.

Material and Method: Investigation of bone marrow structural features and blood parameters was performed in sexually mature Wistar male rats $(\mathrm{n}=84)$.

Results: Exposure to increased amounts of heavy metal salts led to the inhibition of erythropoiesis and leukopoiesis, as well as a synchronized increase in the number of megakaryocytes which was clearly reflected in the blood: the number of erythrocytes, leukocytes and Hb decreased, and the number of platelets increased. These changes in the blood and bone marrow were less pronounced when vitamin $\mathrm{E}$ was used as an adjuster.

Conclusion: When increased amounts of HMS enter the rats' bodies, suppression of erythropoiesis and leukocytopoiesis occurs while thrombocytopoiesis increases. These changes depend on the period of intake of heavy metal salts. The adjustment of vitamin E reduces the severity of the cytotoxic effect of heavy metals and improves readaptation in the recovery period.
\end{abstract}

Key Words: Heavy metal salts, Vitamin E, Hematopoietic system, Bone marrow

\section{INTRODUCTION}

Nowadays hemato-ecological problems are becoming considerably urgent and research is being conducted in this area considering the impact of exogenous factors on biocoenosis. Some of the most powerful pollutants are heavy metal salts (HMS), and in some districts of the Sumy region of Ukraine, their concentrations exceed the maximum permissible range in the water and soil (1). Unfortunately, relatively little research has been devoted to the study of the impact of heavy metal compounds (HMC) on the hematopoietic system despite the rather clear impact of these factors on the majority of organs (2). Moreover, the research available on this theme is devoted only to blood, or only to the hematopoietic system in most cases $(3,4)$.

Qualitative and quantitative blood indicators reflect the function of the hematopoietic system and the operation of other internal organs. The influence of pathogenic factors related to HMS on the process of hematopoiesis may occur through their direct impact on the bone marrow (BM) or indirect damage of other internal organs (5). Their negative effects have been listed as lipid peroxidation induction,

(Turk Patoloji Derg 2018, 34:73-81)

Received : 30.05.2017 Accepted : 18.07.2017 competitive replacement of essential trace elements in the structure of hydroxyapatite, deactivation of enzyme systems, DNA damage and so on (6). All these negative impacts can occur in the process of hematopoiesis, and this is reflected in the peripheral blood.

Recently more attention has been paid to the investigation of changes in hematopoietic tissue. This has been achieved by means of trephine biopsy of the iliac bone and preparation of histological specimens that allow evaluation of the parenchymal component of bone marrow and changes in the stroma, which play a regulatory role in the proliferation and maturation of hematocytes (7).

Another important objective of modern medicine is the search of adequate corrective and preventive ways that increase body resistance to the conditions of constantly growing urbanization and technological progress that lead to rapid contamination of the environment.

The purpose of our work was the study of the laboratory parameters of blood and morphological changes of bone marrow in rats exposed to increased amounts of HMS

Correspondence: Anatolii ROMANIUK

Sumy State University, Department of Pathology, SUMY, UKRAINE

E-mail: pathomorph@gmail.com Phone: +38 0977155524 
to investigate the possible correction of the changes with vitamin $\mathrm{E}$.

\section{MATERIAL and METHODS}

The investigation of bone marrow structural features and blood parameters was performed in sexually mature Wistar male rats (4 months old, $n=84$ ), considering the impact of the animals' ages on the process of hematopoiesis. All investigations were performed in accordance with "General ethical animal experimentation" (Kyiv, 2001) and the Helsinki Declaration of the General Assembly of the World Medical Association (2000). Rats were kept on a standard diet (except some peculiarities in water consumption) in the vivarium at $20-25^{\circ} \mathrm{C}$ temperature, no more than $50 \%$ humidity, and at day/night light mode.

The distribution of the animals into the groups was as follows:

The first group included three series of rats (12 rats in each series). The first series was used as control and the animals drank ordinary water. In the second series, the rats received aqueous mixture of heavy metal salts in the concentration appropriate for the Sumy region and containing $5 \mathrm{mg} / \mathrm{l} \mathrm{zinc}$ $\left(\mathrm{ZnSO}_{4} \times 7 \mathrm{H}_{2} \mathrm{O}\right), 1 \mathrm{mg} / \mathrm{l}$ copper $\left(\mathrm{CuSO}_{4} \times 5 \mathrm{H}_{2} \mathrm{O}\right), 10 \mathrm{mg} / \mathrm{l}$ iron $\left(\mathrm{FeSO}_{4}\right), 0.1 \mathrm{mg} / \mathrm{l}$ manganese $\left(\mathrm{MnSO}_{4} \times 5 \mathrm{H}_{2} \mathrm{O}\right), 0.1$ $\mathrm{mg} / \mathrm{l}$ lead $\left(\mathrm{Pb}\left(\mathrm{NO}_{3}\right)_{2}\right)$, and $0.1 \mathrm{mg} / \mathrm{l}$ chromium $\left(\mathrm{K}_{2} \mathrm{Cr}_{2} \mathrm{O}_{7}\right)$ (1). In the third series, the rats received the same heavy metal nsalts mixture with vitamin E correction $(9.1 \mathrm{mg} / \mathrm{kg}$ of $10 \%$ oil oral solution). The animals' dosage calculation was based on the average daily therapeutic dose for adults. To examine the effects of subacute and chronic exposure to HMS on the blood and hematopoiesis, 6 animals in each series of the first group were removed from the experiment by decapitation under ether anesthesia on the 30th and 90th days of the study.

The second group, including four series of laboratory animals with 12 rats in each series, was used to investigate the readaptation process. The first series was control. The second included rats that had been consuming a mixture of heavy metal salts solution for 90 days and then moved to ordinary drinking water. In the third series, the rats had been consuming a mixture of heavy metal salts solution with vitamin $\mathrm{E}$ correction for 90 days and had then been moved to ordinary drinking water and continued to use vitamin E. In the fourth series, the animals had been consuming a mixture of heavy metal salts solution for 90 days and had then started to use ordinary drinking water with vitamin $\mathrm{E}$. The process of rapid and remote readaptation was examined by taking 6 animals in each series out of the experiment on the 30th and 90th days.
Blood obtained from the rats ' aorta served as the material for laboratory research in which the number of erythrocytes, leukocytes, platelets, hemoglobin $(\mathrm{Hb})$, erythrocyte sedimentation rate, and the levels of $\mathrm{Ca}, \mathrm{Na}, \mathrm{K}$, creatinine and urea were determined when the rats were taken out of the experiment.

The study of structural bone marrow peculiarities was performed using the femur. The material was fixed in $10 \%$ buffered formalin solution. Decalcification had been conducted with EDTA solution ( $\mathrm{pH}$ 7.0) for 14 days, with daily change of the solution. After standard tissue processing, $4 \mu$-thick sections were taken from paraffin-embedded tissues and stained for $\mathrm{H} \& \mathrm{E}$. In order to differentiate erythropoietic and leukopoietic lines of hematopoiesis, immunohistochemical studies were performed to determine the receptors to myeloperoxidase, CD3 and CD79a. Unfortunately, cytological examination and quantitative assessment of the stromal component could not be performed due to the technical difficulties.

The measurement of the size of microspecimen constituent elements was conducted in the environment of the «Digimizer» morphometric program (Figure 1). Obtaining and storage of the images was carried out by means of the digital image output system «SEO Scan» (Ukraine). Statistical calculations were performed using Microsoft Excel 2010 and Attestat 12.0.5. Non-parametric tests were performed with the Mann-Whitney $U$ test while the Spearman correlation test was used in correlation analyses. The results were considered statistically reliable at a probability level of more than $95 \%(\mathrm{p}<0.05)$.

\section{RESULTS}

Both upwards and downwards variations in blood test indicators were found (Figure 2), establishing the dynamic changes in blood under the influence of HMS and their adjustment with vitamin $\mathrm{E}$, as the duration of the experiment was prolonged. Blood counts showed the decrease in erythrocytes, leukocytes and $\mathrm{Hb}$, and the increase of platelets while rats were receiving HMS.

After day $30, \mathrm{Hb}$ decreased by $11 \%(\mathrm{p}<0.01)$ and the number of erythrocytes by $23.3 \%(\mathrm{p}<0.01)$ in rats of the second series of the first group. There was a $4.6 \%$ increase in the number of leukocytes and $2.5 \%$ increase in the number of platelets but were not found to be significant ( $\mathrm{p}=0.11$ and $\mathrm{p}=0.08$, respectively). With prolonged duration of receiving exogenous pollutants (on day 90), a consistent decrease in $\mathrm{Hb}$ levels and in the number of leukocytes and erythrocytes was observed $(18.4 \%, 32.5 \%, 15.3 \%$, respectively) while 
platelets were increased by $11 \%(\mathrm{p}<0.01)$. The changes were not so impressive in the blood of rats in the third series of the first group. On the 90th day, $\mathrm{Hb}$ indicators decreased by
$6.6 \%$, the number of erythrocytes by $23.3 \%$ and leukocytes by $13.2 \%$, while the number of platelets conversely increased by $8.2 \%(\mathrm{p}<0.01)$.


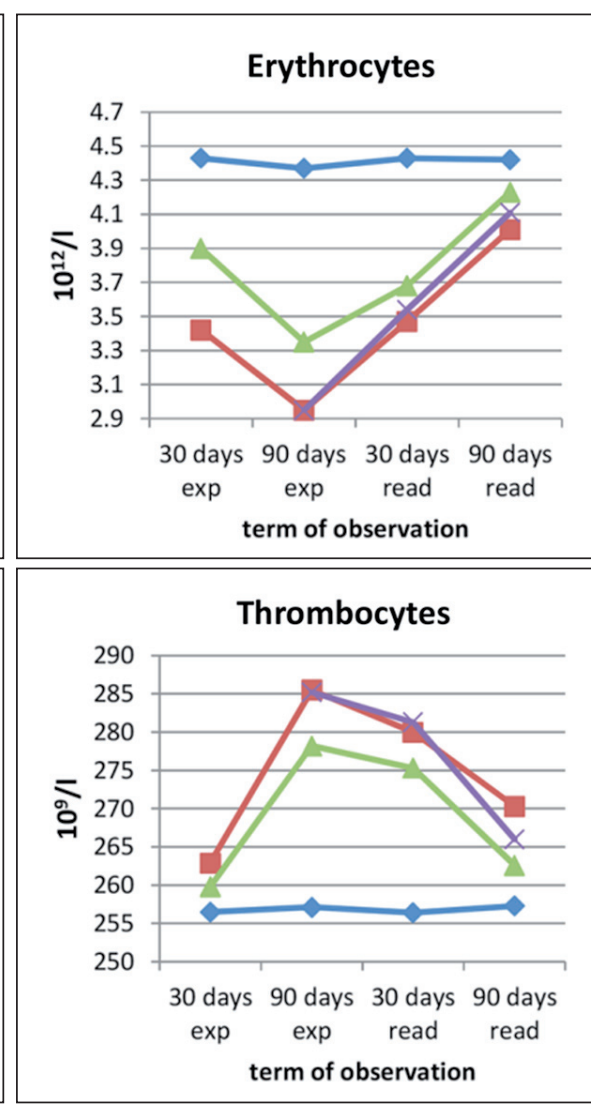

Figure 1: A screen shot as an example of working with images in the environment of the «Digimizer» morphometric program.
Figure 2: Indicators of rats' complete blood counts. Exp: the period of the experiment, Read: the period of readaptation.

Blue line: control group, red line: rats that drank water with HMS, green line: rats that drank water with HMS and were administered vitamin $\mathrm{E}$, violet line: rats that were administered vitamin $\mathrm{E}$ during rehabilitation after HMS. 
In the readaptation process, blood indicators gradually normalized, but did not reach the levels of animals in the control group. The tempo of this process also depended on the conditions of readaptation. Thus, in rats of the second series of the second group, increases in $\mathrm{Hb}$ levels and erythrocyte and leukocyte numbers were observed $(12.6 \%, 35.9 \%, 8.4 \%$, respectively), while platelet numbers decreased by $5.3 \%(\mathrm{p}<0.01)$ on the 90 th day. Increases in $\mathrm{Hb}$ levels and erythrocyte and leukocyte numbers were $17.5 \%$, $39.3 \%, 11.5 \%$, respectively, in animals of the fourth series of the second group; and $8.9 \%, 26.3 \%, 11.3 \%$, respectively, in rats of the third series of the second group. For these last two groups, decreases in platelet numbers were found at rates of $6.8 \%(\mathrm{p}<0.01)$ and $5.6 \%(\mathrm{p}<0.01)$, respectively.

The changes in blood biochemical parameters in the rats of the second and third series of the first group had similar dynamics (Table I), which was expressed by decreases in the measured values of $\mathrm{Ca}(\mathrm{p}<0.01)$ and $\mathrm{K}(\mathrm{p}=0.01)$ and by increases of $\mathrm{Na}(\mathrm{p}<0.01)$, creatinine $(\mathrm{p}=0.04)$ and urea $(\mathrm{p}<0.01)$. During readaptation, these indicators gradually normalized, but in most cases they did not reach the values of animals in the control group. The speed of recovery depended on readaptation conditions (whether adjustment with vitamin $\mathrm{E}$ was present or absent) and readaptation duration.

In the study of morphological features of bone marrow structure, we found that it undergoes quantitative and qualitative changes during the experiment, both at the level of the epiphysis and the diaphysis (Figure 3,4). A gradual decrease in the number of erythropoietic and leukopoietic cells with simultaneous increase in the number of megakaryocytes was taking place (control group indicators were $5.25 \pm 1.42 \%, \quad 14.75 \pm 1.42 \%, 0.16 \pm 0.05 \%$ at the epiphysis level and $17.83 \pm 0.75 \%, 51.17 \pm 3.27 \%, 0.16 \pm 0.05 \%$ at the diaphysis level, respectively (8)), which reached maximum values on the 90th day of the experiment. Thus, the area of erythropoiesis in the second series of rats was reduced by $30 \%$ at the epiphysis level $(\mathrm{p}=0.03)$ and by $17.8 \%$ at the diaphysis level ( $\mathrm{p}=0.025)$ in 3 months; the area of leukopoiesis decreased by $6.1 \%(\mathrm{p}=0.16)$ and $13.7 \%$ $(\mathrm{p}<0.01)$, respectively. The number of megakaryocytes increased by $27 \%$.

Adipose tissue and sinusoids crowded with blood replaced the area being released from hematopoietic tissue during the experiment (normally they accounted for $11 \pm 2 \%$ and $18.7 \pm 2.1 \%$, respectively) (8).

Hematopoiesis indicators gradually returned to normal during readaptation, but they did not reach the values of the control group of animals (Figure 5). The speed and the completeness of recovery depended on the use of vitamin $\mathrm{E}$ for adjustment. In rats of the second series, erythropoiesis increased by $35.6 \%$ and $18.1 \%(\mathrm{p}=0.01)$ respectively in the femur segment, leukopoiesis increased by $9.5 \%(\mathrm{p}=0.045)$ and $8.4 \%(\mathrm{p}=0.01)$, and thrombopoiesis decreased by $18 \%$ on the 90th day of readaptation. In animals of the third series, the area occupied by erythropoiesis increased by $29.5 \%(\mathrm{p}=0.01)$ at the epiphysis level and by $18.5 \%(\mathrm{p}<0.01)$ at the diaphysis level. Leukopoietic areas increased by $5.8 \%$

Table I: Indicators of the biochemical blood tests of the animals.

\begin{tabular}{|c|c|c|c|c|c|c|c|c|c|c|c|c|c|c|}
\hline & \multicolumn{6}{|c|}{ Group I } & \multicolumn{8}{|c|}{ Group II } \\
\hline & \multicolumn{2}{|c|}{ Series 1} & \multicolumn{2}{|c|}{ Series 2} & \multicolumn{2}{|c|}{ Series 3} & \multicolumn{2}{|c|}{ Series 1} & \multicolumn{2}{|c|}{ Series 2} & \multicolumn{2}{|c|}{ Series 3} & \multicolumn{2}{|c|}{ Series 4} \\
\hline & $\begin{array}{c}\text { 30th } \\
\text { day }\end{array}$ & $\begin{array}{l}\text { 90th } \\
\text { day }\end{array}$ & $\begin{array}{l}\text { 30th } \\
\text { day }\end{array}$ & $\begin{array}{c}\text { 90th } \\
\text { day }\end{array}$ & $\begin{array}{l}\text { 30th } \\
\text { day }\end{array}$ & $\begin{array}{l}\text { 90th } \\
\text { day }\end{array}$ & $\begin{array}{c}\begin{array}{c}\text { 30th } \\
\text { day }\end{array}\end{array}$ & $\begin{array}{l}\text { 90th } \\
\text { day }\end{array}$ & $\begin{array}{l}\text { 30th } \\
\text { day }\end{array}$ & $\begin{array}{l}\text { 90th } \\
\text { day }\end{array}$ & $\begin{array}{c}\text { 30th } \\
\text { day }\end{array}$ & $\begin{array}{c}\text { 90th } \\
\text { day }\end{array}$ & $\begin{array}{l}\text { 30th } \\
\text { day }\end{array}$ & $\begin{array}{l}\text { 90th } \\
\text { day }\end{array}$ \\
\hline \multirow{2}{*}{$\mathrm{Ca}$} & 3.03 & 3.0 & $2.75^{* *}$ & $2.81^{*}$ & $2.87^{*}$ & $2.81^{* *}$ & 3.03 & 3.01 & 2.88 & 2.94 & 2.84 & $2.98^{* *}$ & 2.87 & $2.96^{*}$ \\
\hline & \pm 0.06 & \pm 0.07 & \pm 0.05 & \pm 0.11 & \pm 0.12 & \pm 0.05 & \pm 0.08 & \pm 0.09 & \pm 0.05 & \pm 0.13 & \pm 0.12 & \pm 0.05 & \pm 0.07 & \pm 0.08 \\
\hline \multirow{2}{*}{$\mathrm{Na}$} & 134.9 & 135.3 & $144.6^{* *}$ & $155^{* *}$ & $140.1^{*}$ & $147.5^{* *}$ & 135.1 & 135.6 & $149.6^{*}$ & $143.8^{* *}$ & 142.3 & $137^{* *}$ & $146.3^{* *}$ & $139.9^{*}$ \\
\hline & \pm 4.1 & \pm 3 & \pm 2.6 & \pm 3.6 & \pm 1.1 & \pm 3.1 & \pm 1.6 & \pm 2.5 & \pm 2.3 & \pm 4.4 & \pm 1.5 & \pm 2.6 & \pm 2.6 & \pm 2.5 \\
\hline \multirow{2}{*}{ K } & 4.68 & 4.7 & $4.3^{*}$ & $3.98^{* *}$ & 4.5 & $4.2^{*}$ & 4.65 & 4.68 & $4.17^{*}$ & $4.37^{* *}$ & 4.3 & $4.55^{* *}$ & 4.2 & $4.45^{* *}$ \\
\hline & \pm 0.32 & \pm 0.33 & \pm 0.14 & \pm 0.15 & \pm 0.23 & \pm 0.1 & \pm 0.27 & \pm 0.17 & \pm 0.1 & \pm 0.12 & \pm 0.14 & \pm 0.16 & \pm 0.18 & \pm 0.23 \\
\hline \multirow{2}{*}{$\mathrm{Cr}$} & 78.7 & 79.1 & $88.3^{* *}$ & $90.4^{* *}$ & $84.8^{*}$ & $87.1^{*}$ & 78.5 & 78.9 & $86.8^{* *}$ & $82.4^{* *}$ & $83.1^{*}$ & $80.1^{* *}$ & $84.5^{* *}$ & $81.7^{* *}$ \\
\hline & \pm 4.9 & \pm 5.6 & \pm 2.3 & \pm 1.2 & \pm 3.3 & \pm 1.7 & \pm 2.7 & \pm 2.4 & \pm 1.9 & \pm 1.8 & \pm 3.1 & \pm 1.3 & \pm 1.9 & \pm 1.6 \\
\hline \multirow{2}{*}{$\mathbf{U}$} & 4.89 & 4.87 & $5.73^{* *}$ & $6.12^{* *}$ & $5.38^{*}$ & $5.73^{* *}$ & 4.85 & 4.83 & 5.63 & $5.15^{*}$ & $5.28^{* *}$ & $4.95^{* *}$ & $5.47^{*}$ & $5.28^{*}$ \\
\hline & \pm 0.35 & \pm 0.21 & \pm 0.52 & \pm 0.46 & \pm 0.29 & \pm 0.19 & \pm 0.19 & \pm 0.28 & \pm 0.26 & \pm 0.38 & \pm 0.15 & \pm 0.22 & \pm 0.45 & \pm 0.4 \\
\hline
\end{tabular}

Ca: Calcium; Na: Sodium; K: Potassium; Cr: Ceatinine, U: Urea.

* The probability value (p) between two independent samples according to the $\mathrm{U}$ criterion on the basis of the Mann-Whitney criterion $\mathrm{p}<0.05$, ${ }^{* *} \mathrm{p}<0.01$. 
$(\mathrm{p}=0.03)$ and $11.4 \%(\mathrm{p}<0.01)$ respectively, and the number of platelets decreased by $23 \%$. Indicators of the third series of animals were as follows: erythropoiesis increased by $35.5 \%$ and $18.9 \%(\mathrm{p}=0.01)$ and leukopoiesis by $10.5 \%$ $(\mathrm{p}=0.03)$ and $9.4 \%(\mathrm{p}=0.01)$, and the number of platelets decreased by $36 \%$. The area occupied by predecessors of $\mathrm{T}$ and B-lymphocytes (CD3 and CD79 $\alpha$ receptors expression) did not show any statistically significant changes $(p>0.05)$ during the experiment and readaptation and it was about $5 \%$.

Comparing the area occupied by leukocyte predecessors to the area of erythropoiesis (the myeloid/erythroid (M:E) ratio), a gradual increase was established (due to more rapid suppression of erythropoiesis) from 1:2.8 (normal) to 1:3.46 (in the 90 days of the experiment). During readaptation, we have observed some optimization of the M:E ratio (1:2.75), but it did reach normal values due to the lack of complete recovery of hematopoiesis.

Laboratory and morphological parameters of the bloodforming system were monitored during the whole period and we established a direct correlation between the number of erythrocytes and erythropoiesis area $(\mathrm{r}=0.71, \mathrm{p}<0.001$ for the epiphysis and $\mathrm{r}=0.67, \mathrm{p}<0.001$ for the diaphysis), as well as between the number of leukocytes and the leukopoietic area $(\mathrm{r}=0.7, \mathrm{p}<0.001$ and $\mathrm{r}=0.87, \mathrm{p}<0.001$, respectively) and the platelet levels and the number of megakaryocytes $(\mathrm{r}=0.47, \mathrm{p}<0.001) . \mathrm{Hb}$ values and their sensitivity were identical to erythrocytes: as the erythropoiesis area became smaller, the rates of $\mathrm{Hb}$ decreased $(\mathrm{r}=0.47, \mathrm{p}<0.001$ and $\mathrm{r}=0.36, \mathrm{p}=0.002$ in the appropriate topography of the femur).

Among the qualitative changes in rats' bone marrows during the experiment, we observed hemorrhages, focal adiposis (due to inhibition of hematopoiesis), myxomatosis phenomena, sinusoidal ectasia, histiocytic infiltration, degenerative changes (atrophy, necrosis and apoptosis phenomena) and others (Figure 6). The intensity of these changes and the rate of their recovery depended on the adjustor availability - changes developed slowly and not in full extent when using vitamin $\mathrm{E}$.

\section{DISCUSSION}

The bone marrow undergoes significant changes during vital activity, which is associated with age characteristics and the impact of the environment $(4,9)$. The study was carried out on 84 rats to determine the impact of increased amounts of HMS on the hematopoietic system. We found that exposure to exogenous pollutants led to the inhibition
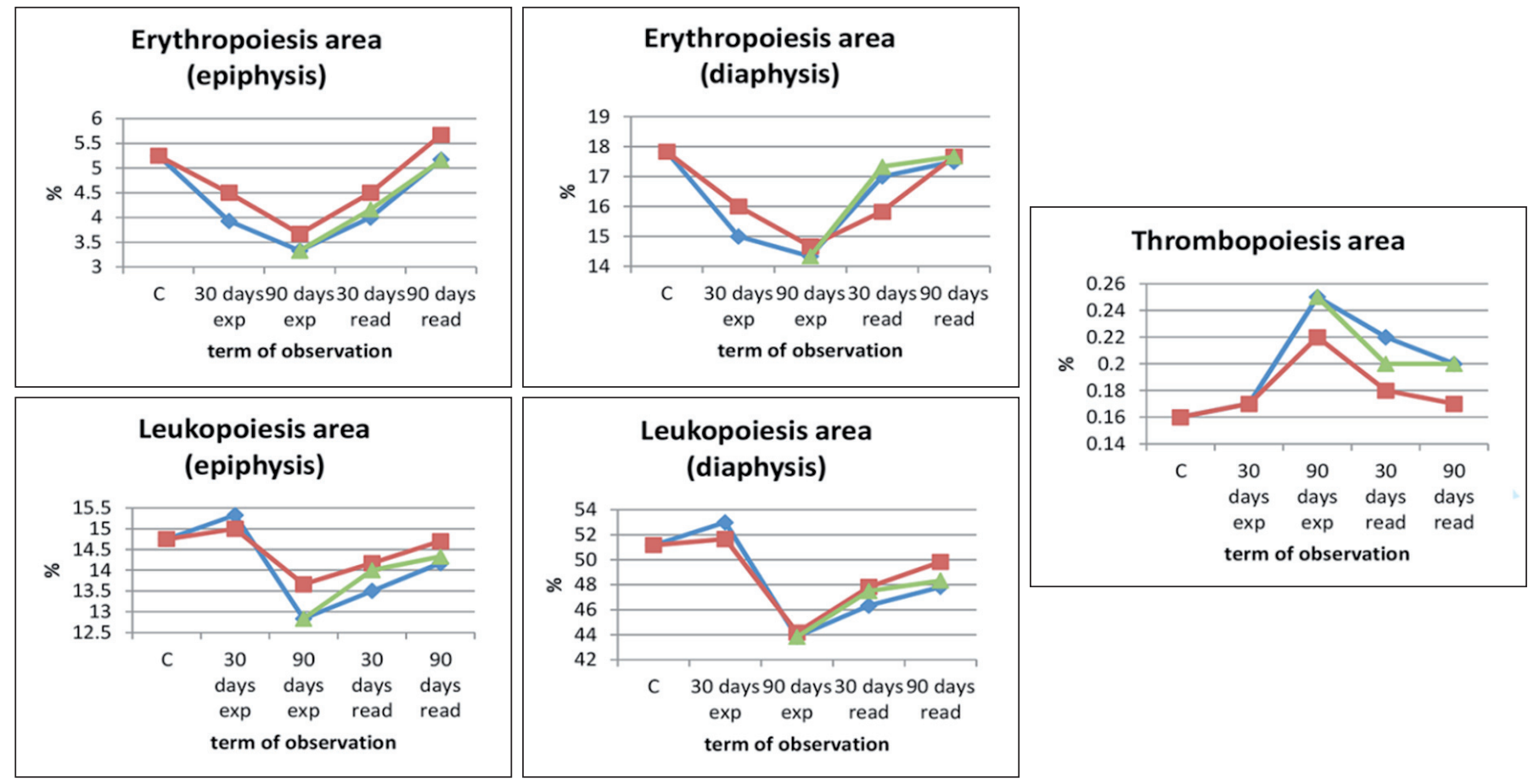

Figure 3: Indicators of bone marrow area that are engaged in various pathways of hematopoiesis in rats.

Exp: The period of the experiment, Read: The period of readaptation, C: indicators in the control series of rats, Blue Line: Rats that drank water with HMS, Red Line: Rats that drank water with HMS and were administered vitamin E, Green Line: Rats that were administered vitamin E during rehabilitation after HMS. 
of erythropoiesis and leukopoiesis and synchronized growth in the number of megakaryocytes which was clearly reflected in the blood: the number of erythrocytes, leukocytes and $\mathrm{Hb}$ decreased, and the number of platelets increased. These changes are associated with the direct and indirect hematotoxic influence of HM, directly affecting the function of hematopoietic cells (increased lipid peroxidation and the formation of active oxygen forms, the DNA destabilization, deactivation of enzyme systems) (6). HM suppresses the proliferative activity of cells and blocks their maturation. The estrogen-resembling activity of HM plays a significant role in the inhibition of hematopoiesis (10), which is reflected in a normal blood test (erythrocytes and $\mathrm{Hb}$ indicators of men are higher and platelet indicators are lower compared to women). Therefore, the increase in the number of HM in the blood enhances their estrogenresembling effect on the bone marrow, considering the presence of estrogen receptors in hematopoietic cells (11). We do not rule out a direct cytotoxic effect of metals on blood corpuscles (3). Reactive thrombocytosis is also associated with slowly progressive anemia, and as a result, the rate of maturation of platelet predecessors increases and their destruction decreases (12). The study showed more pronounced changes in hematopoiesis - the blood system, namely during the subacute period of the experiment (30 days) with a gradual slowing on the 90th day, which is associated with activation of endogenous adaptive compensatory processes in rats when their living conditions change.

As seen from the results of the study, significant changes in biochemical blood tests (increased urea, creatinine, dismicroelementosis) occur due to the nephrotoxic effects of HMS. There are also negative effects on bone tissue

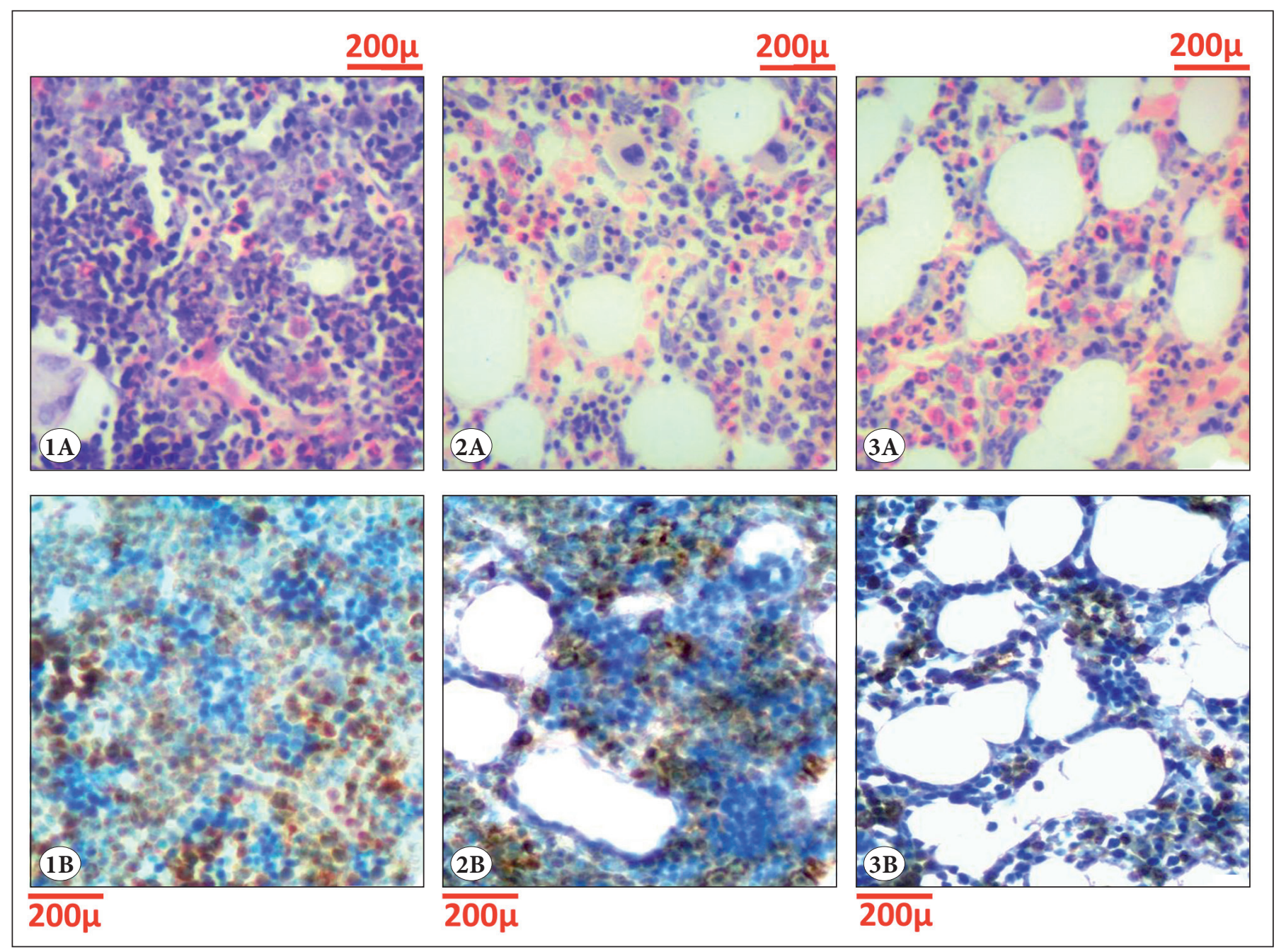

Figure 4: Longitudinal section of rat femur on diaphysis. 1) Control group, 2) Rats of the second series of the first group (30th day), 3) Rats of the second series of the first group (90th day). (A: H\&E; x400, B: Immunohistochemical determination of myeloperoxidase receptors; $\times 400)$. 
and the parathyroid gland (initial decrease of Ca because of probable inhibition of parathormone synthesis and subsequent increase in the washout of calcium from the hydroxyapatite bone structure) $(13,14)$. Indirect effects of HMS on hematopoiesis are realized precisely because of increasing metabolic products of nitrogenous bases and dismicroelementosis.

Erythropoietic tissue was found to be the most sensitive part of bone marrow. Its inhibition reaches 36.6\% (leukopoiesis is maximally inhibited by $14 \%$ ), which manifests itself as a rapidly arising anemia. Anemia can stimulate thrombocytosis, which is also provoked by heavy metals. It seems that the least affected part of hematopoiesis is lymphopoiesis. Other studies are needed to see whether lymphoid tissue is affected in the other parts of the lymphoid system, i.e. the thymus, spleen, lymph nodes, etc.
As HMS strongly inducts lipid peroxidation, we used vitamin $\mathrm{E}$ as an adjustment agent that has a strong protective effect on lipids and DNA as a common antioxidant (15). We observed the protective effects of vitamin $\mathrm{E}$, as the reparative changes occurred more fully in vitamin $\mathrm{E}$ administered rats. It is also stated that vitamin E does not have any significant negative effect on the process of hematopoiesis in mature rats (16). However, the changes that occurred during the experiment were not completely eliminated in any case even with the constant administration of vitamin E. This finding emphasizes the cumulative properties of exogenous pollutants. Also, we have not observed any significant difference in the hematopoiesis recovery rate during different periods of rehabilitation, indicating the gradual and slow excretion of HMS.

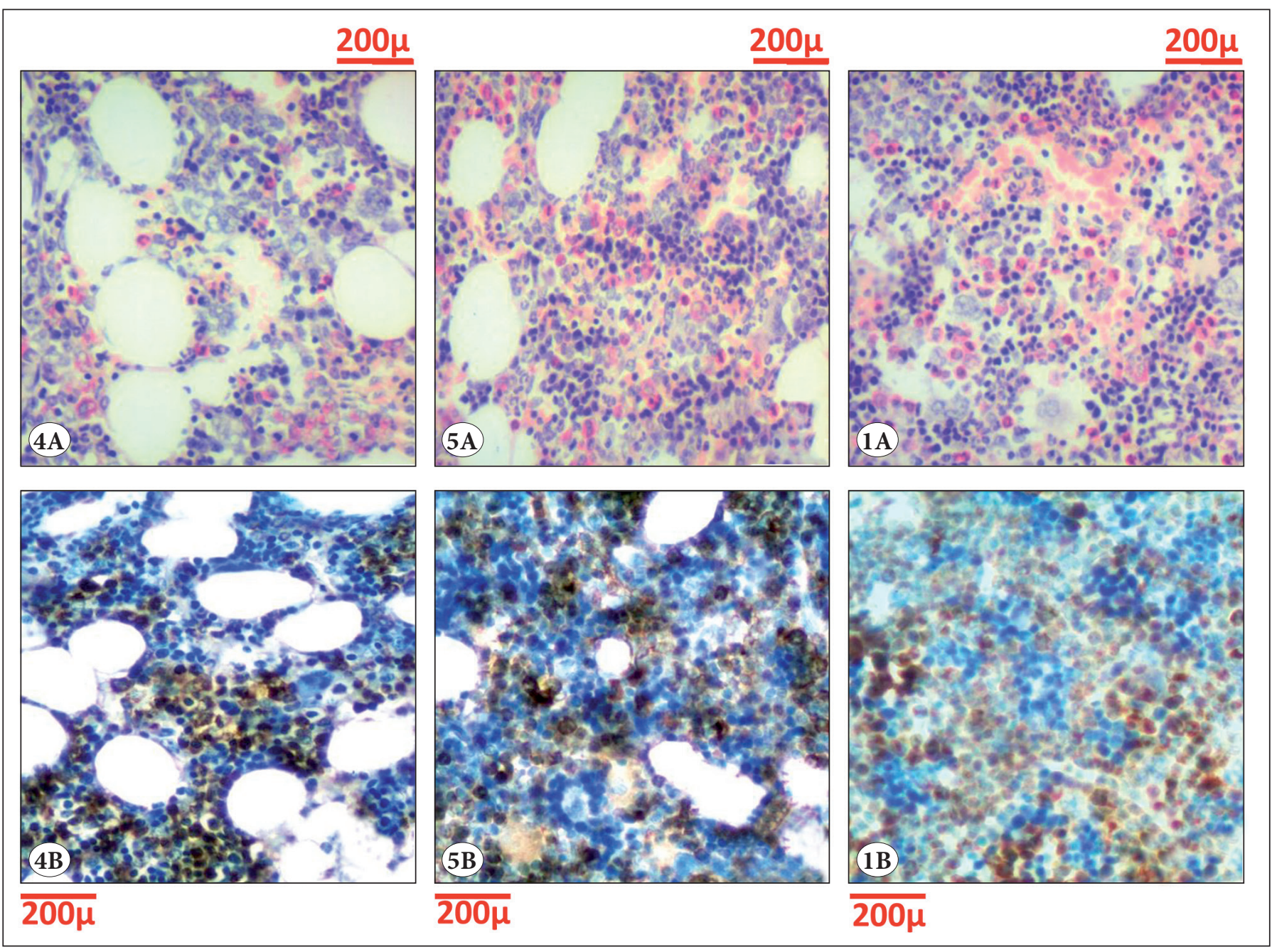

Figure 5: Longitudinal section of rat femur on the diaphysis. 1) Control group, 4) Rats of the second series of the first group (30th day), 5) Rats of the second series of the first group (90th day). (A: H\&E; $x 400$, B: Immunohistochemical determination of myeloperoxidase receptors; $\mathrm{x} 400)$. 

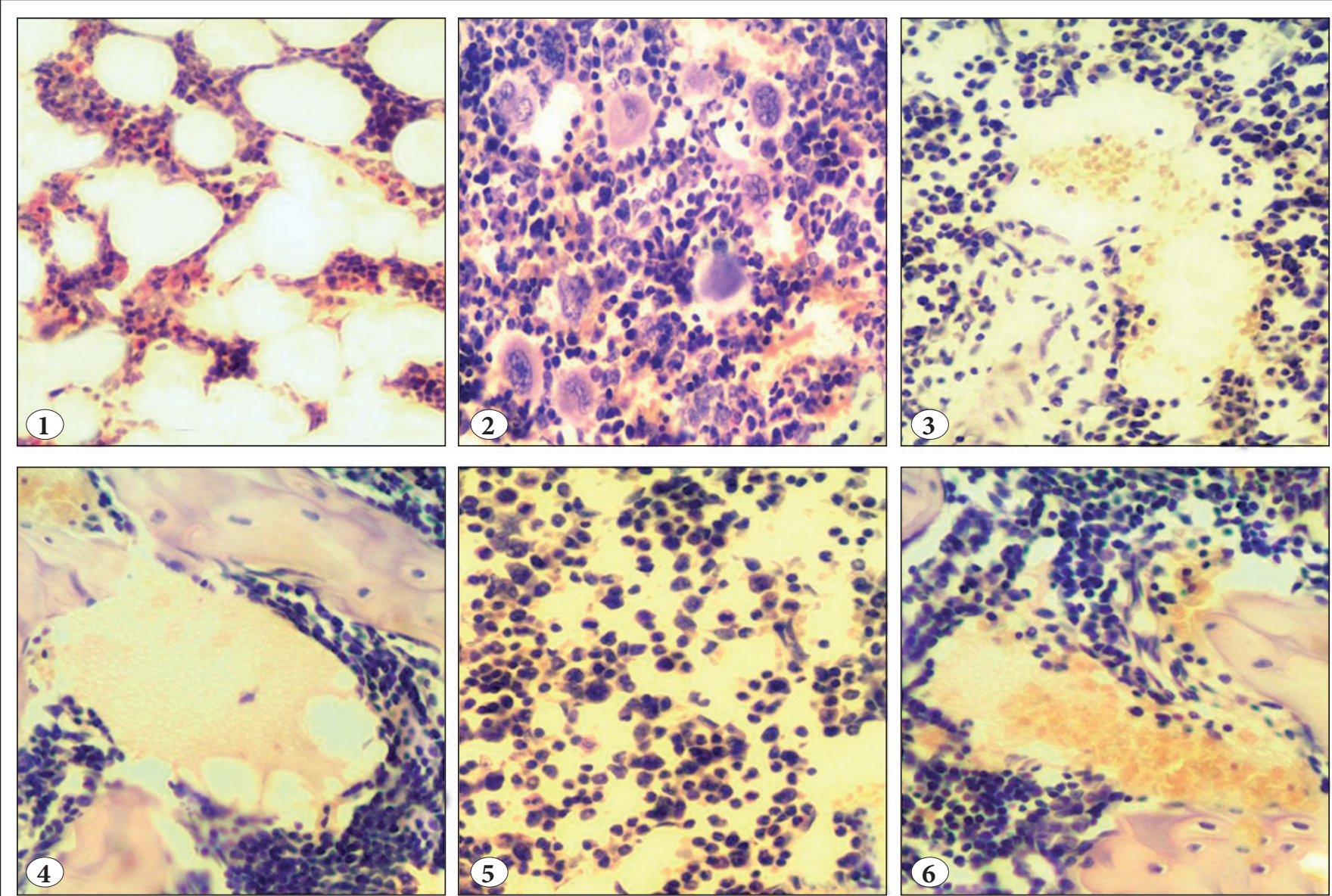

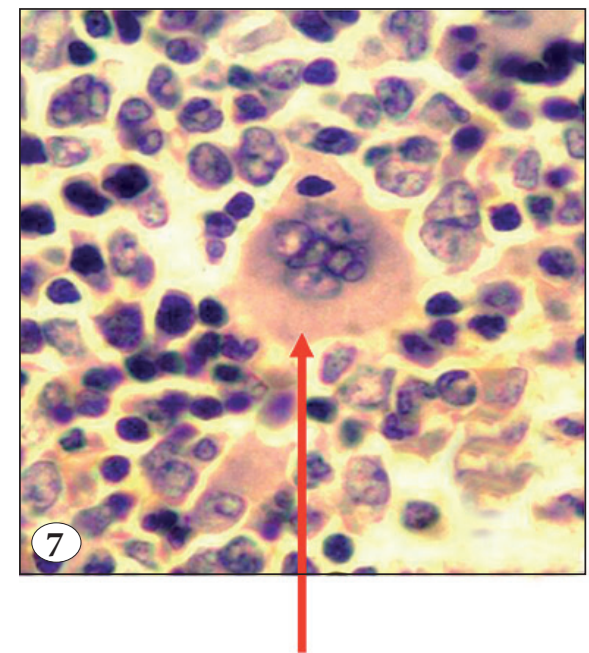

(A)

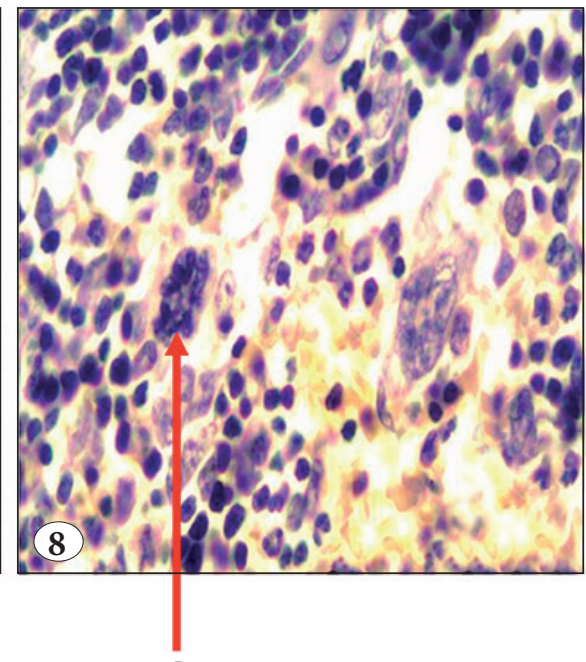

(B)

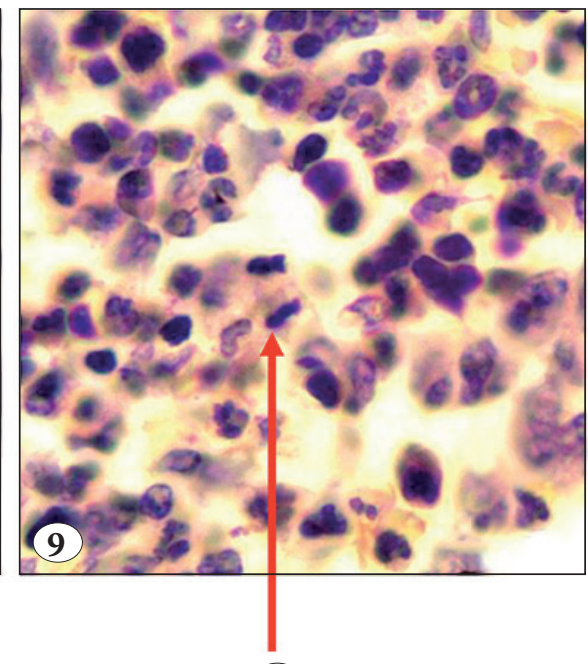

(C)

Figure 6: Qualitative changes in rats' bone marrow influenced by HMS. 1) Focal lipomatosis (H\&E; x100). 2) Clusters of megakaryocytes (H\&E; x100). 3) Sinusoidal ectasia (H\&E; x100). 4) Myxomatosis (H\&E; x100). 5) Atrophy (H\&E; x100). 6) Hemorrhages (H\&E; x100). 7) Emperipolesis (H\&E; x400). 8) Dysmegakaryopoiesis (H\&E; x400). 9) Apoptosis (H\&E; x400). (A: Megakaryocyte with a leukocyte inside, B: Wrinkled megakaryocyte with symptoms of kariopiknosis and chromatin condensation, C: Cells in the state of apoptosis) 
In conclusion, the bone marrow is very vulnerable and also very sensitive to the variability of living conditions, which leads to both a parenchymal and stromal reaction. Increased amounts of heavy metal salts oppress erythropoiesis and leukocytopoiesis in rats while thrombotcytopoiesis occurs, as demonstrated in our study. The level of qualitative and quantitative destructive changes depends on the direct and indirect effects of exogenous pollutants. More pronounced changes were observed during the subacute period of the experiment (first 30 days) with gradual slowing on the 90th day, which is associated with activation of endogenous adaptive-compensatory processes in rats when living conditions change.

The adjustment of vitamin E reduces the severity of the cytotoxic effect of heavy metals and improves readaptation in the recovery period. However, even with constant use of vitamin $\mathrm{E}$, the full range of morphological changes of the bone marrow does not reach normal levels, which reflects the cumulative properties of heavy metal salts in the body.

\section{CONFLICT of INTEREST}

The authors declare no conflict of interest.

\section{REFERENCES}

1. Yakovtsova AF, Gubina-Vakulik GI, Sibbons P, Gorbatch TV, Ansari T, Markovsky VD, Sorokina IV, Potapov SN, Gargin VV. Morphological and chemical changes in the medulla of the adrenal glands of progeny from parents who smoked preconception: An experimental study in rats. Comp Clin Pathol. 2007;16:131-7.

2. Romaniuk A, Korobchanska AB, Kuzenko Y, Lyndin M. Mechanisms of morphogenetic disorders in the lower jaw under the influence of heavy metal salts on the body. Interv Med Appl Sci. 2015;7:49-52.

3. Saljooghi AS, Delavar-Mendi F. The effect of mercury in iron metabolism in rats. J Clinic Toxicol. 2012:3:1-5.

4. Hounkpatin AY, Edorh PA, Guédénon P, Alimba CG, Ogunkanmi A, Dougnon TV, Boni G, Aissi KA, Montcho S, Loko F, Ouazzani N, Mandi L, Boko M, Creppy EE. Haematological evaluation of Wistar rats exposed to chronic doses of cadmium, mercury and combined cadmium and mercury. Afr J Biotechnol. 2013;12:37317.
5. Travlos GS. Histopathology of bone marrow. Toxicol Pathol. 2006;34:566-98.

6. Jaishankar M, Tseten T, Anbalagan N, Mathew BB, Beeregowda $\mathrm{KN}$. Toxicity, mechanism and health effects of some heavy metals. Interdiscip Toxicol. 2014;7:60-72.

7. Frenkel MA, Chigrinova EV, Kupryshina NA, Pavlovskaia AI. Diagnostic value of study of bone marrow trepanobiopsy imprints in patients with non-Hodgkin's lymphomas. Klin Lab Diagn. 2007;11:44-7.

8. Romaniuk A, Lyndina Yu, Sikora V, Lyndin M, Karpenko L, Gladchenko O, Masalitin I. Structural features of bone marrow. Interv Med Appl Sci. 2016;8:121-6.

9. Cline JM, Maronpot RR. Variations in the histologic distribution of rat bone marrow cells with respect to age and anatomic site. Toxicol Pathol. 1985;13:349-55.

10. Iavicoli I, Fontana L, Bergamaschi A. The effects of metals as endocrine disruptors. J Toxicol Environ Health B Crit Rev. 2009;12:206-23.

11. Schulze H, Shivdasani RA. Mechanisms of thrombopoiesis. J Thromb Haemost. 2005;3:1717-24.

12. Koloskov AV, Saparkina MB, Philippova OI, Stolitsa AA. Reactive thrombocytosis. Transfusiology. 2012;13:359-71.

13. Kuzenko Y, Romanyuk A, Korobchanskaya A, Karpenko L. Periodontal bone response under the influence of $\mathrm{Cr}(\mathrm{VI})$. Osteologický Bulletin. 2014;1:23-7.

14. Sabath E, Robles-Osorio ML. Renal health and the environment: Heavy metal nephrotoxicity. Nefrologia. 2012;32:279-86.

15. Górnicka M, Drywień M, Frąckiewicz J, Dębski B, Wawrzyniak A. Alpha-tocopherol may protect hepatocytes against oxidative damage induced by endurance training in growing organisms. Adv Clin Exp Med. 2016;25:673-9.

16. Lucas EA, Chen TY, Chai SC, Devareddy L, Juma S, Wei CI, Tripathi YB, Daggy BP, Hwang DF, Arjmandi BH. Effect of vitamin $\mathrm{E}$ on lipid parameters in ovariectomized rats. J Med Food. 2006;9:77-83. 